\title{
USO DE ORQUIECTOMIA UNILATERAL PARA MELHORIA DO PADRÃO ESPERMÁTICO DE TOURO COM DEGENERAÇÃO TESTICULAR
}

\author{
Antonio Campanha Martinez ${ }^{1}$, José Mário Gonçalves², Barbara Cristina Mazzucatto ${ }^{1}$, \\ Welber Daniel Zanetti Lopes ${ }^{3}$, Rodrigo Fernando Santana De Lucia ${ }^{4}$. \\ ${ }^{1}$ Docente Universidade Estadual De Maringá - Campus Regional de Umuarama; \\ Departamento de Medicina Veterinária; Laboratório de Criação e Reprodução \\ Animal. acmartinez@uem.br \\ ${ }^{2}$ Médico Veterinário Pós-Graduando em Residência Médico Veterinária, UEM - \\ Umuarama. \\ ${ }^{3}$ Docente Universidade Federal de Goiás. \\ ${ }^{4}$ Médico Veterinário Autônomo - Geração Tecnologia Reprodutiva. \\ Recebido em: 08/09/2015 - Aprovado em: 14/11/2015 - Publicado em: 01/12/2015 \\ DOI: http://dx.doi.org/10.18677/Enciclopedia_Biosfera_2015_242
}

\begin{abstract}
RESUMO
A degeneração testicular tem sido extensivamente estudada, com origem multifatorial e localização unilateral ou bilateral. Neste estudo, ao exame clínico, um touro Nelore mostrou o testículo direito aparentemente normal e alterações anatômicas no testículo esquerdo. Durante o exame físico, revelou-se um aumento do volume testicular, firme e sem mobilidade no escroto. Em três amostras de sêmen, com um intervalo entre elas de 65 dias, a avaliação dos padrões andrológicos e morfológicos para sêmen foram motilidade $60 \%$, vigor espermático 3 , usando a escala proposta por CBRA (1998), com aumentos de problemas da morfologia espermática sendo sugestivo de degeneração testicular. Depois da terceira colheita de sêmen optou-se pela remoção do testículo afetado através de uma orquiectomia unilateral. No final da intervenção foram colhidas amostras dos testículos para avaliação histopatológica, onde observou-se extensa área de necrose coagulativa. Com 90 dias de pós-operatório, recolheu-se novamente uma amostra seminal para reavaliação de padrões morfológicos e andrológicos, constatando-se uma melhora significativa nos padrões espermáticos com motilidade de $80 \%$, vigor 4 e turbilhonamento 3 , além de normalidade de problemas de morfologia espermática. A técnica de orquiectomia unilateral pode ser viável para os touros que têm grave degeneração testicular unilateral.
\end{abstract}

PALAVRAS-CHAVE: cirurgia reprodutiva, exame andrológico, touro, sêmen.

\section{ORCHIECTOMY UNILATERAL USE FOR IMPROVING THE STANDARD WITH BULL SPERMATIC DEGENERATION TESTICULAR}

\begin{abstract}
Testicular degeneration has been extensively studied, with multifactorial origin and localization unilateral or bilateral. In this study, a Nelore bull in clinical examination showed the testicle apparently normal law and anatomical changes in the left testicle, continuing with the physical examination showed an increase in testicular volume,
\end{abstract}


firm and without mobility in the scrotum. In three semen samples with an interval of 65 days between the samples for evaluation of andrologic and morphological patterns found values for semen motility $60 \%$, sperm vigor 3 , using the scale proposed by CBRA (1998), with increases of sperm morphology problems being suggestive of testicular degeneration. After the third collection of semen opted for the removal of the affected testicle through a unilateral orchiectomy. At the end of the intervention were collected samples of the testis, and subjected to the preparation of histological slide. Histologically observed extensive areas of coagulative necrosis. With 90 postoperative days, it collected again a seminal sample to revaluation of morphological and andrologic standards, though there is a significant improvement in sperm motility patterns with $80 \%$, and vigor 4 . And without morphology problems sperm. The unilateral orchiectomy technique may be feasible for bulls that have severe unilateral testicular degeneration.

KEYWORDS: bull, semen examination, surgery

\section{INTRODUÇÃO}

Os testículos dos bovinos situam-se na bolsa testicular, com localização inguinal e posicionados verticalmente, sendo suas principais funcionalidades a endócrina e espermatogênica. Os testículos devem apresentar-se simétricos, móveis na bolsa testicular e sem sinais de dor durante a palpação. Qualquer assimetria, alteração em sua conformação ou em consistência testicular pode ser indicativo de processo patológico.

Nos mamíferos, a espermatogênese depende da manutenção ideal da temperatura escrotal, em touros deve ser mantida entre 2 a $6^{\circ} \mathrm{C}$ abaixo da temperatura abdominal, a elevação de temperatura ambiente pode causar degeneração testicular por interferir no mecanismo termorregulador e tem sido o principal fator de subfertilidade nos reprodutores bovinos.

A manutenção térmica escrotal é determinada pela temperatura ambiente, umidade, temperatura corporal, quantidade de calor eliminada pelo escroto, variação anatômica do escroto, bem como integridade da pele escrotal (BICUDO \& SIQUEIRA, 2007).

A degeneração testicular vem sendo intensamente estudada em bovinos sendo caracterizada por processos degenerativos e necróticos das células germinativas. Desencadeada por causas de origem multifatorial, pode apresentar-se de forma uni ou bilateral, dependendo da causa, se é temporária ou permanente e variando de discreta a severa sob o ponto de vista patológico (CAMP, 1997). Como a etiologia do processo, na maioria dos casos, relacionados a um dano tecidual local, seja por morte celular ou dano oxidativo, nenhum tratamento hormonal tem valor (BICUDO \& SIQUEIRA, 2007).

O estabelecimento de diagnósticos e prognósticos seguros para confirmação da degeneração testicular depende da realização de uma detalhada anamnese, exame clínico geral e andrológico, também a avaliação dos aspectos físicos e morfológicos do sêmen em exames consecutivos, visando evitar o descarte de touros com base em apenas uma avaliação, pois quando recuperados, podem readquirir a fertilidade normal. O presente trabalho teve por objetivo avaliar a eficácia da orquiectomia unilateral como tratamento alternativo em um touro com degeneração testicular. 


\section{MATERIAL E MÉTODOS}

Um touro Nelore com histórico de deficiência reprodutiva há mais de 2 anos. Durante o exame clínico constatou-se que o testículo direito apresentava-se aparentemente normal (CBRA, 1998), diferente do testículo esquerdo, onde notouse um aumento de volume testicular, de consistência firme e sem mobilidade na bolsa testicular ainda com significante acúmulo de líquido no espaço intersticial (Figura 1A), Foi realizado um exame ultrassonográfico com transdutor linear de $7,5 \mathrm{MHz}$ (Landwind), com a finalidade de observar o parênquima testicular.

Foram obtidas 3 amostras seminais por eletroejaculação, com intervalo de 65 dias entre as amostras, para avaliação dos padrões andrológicos e morfológicos e foram observados valores para motilidade seminal de $60 \%$, vigor espermático 3 e turbilhonamento 3, utilizando a escala proposta por CBRA (1998), com crescentes aumentos de morfologia espermática sendo sugestivas de degeneração testicular. Após a terceira coleta de sêmen optou-se pela retirada do testículo comprometido através de uma orquiectomia unilateral (Figura 1B).

Com o animal em jejum prévio de 12 horas, foi estabelecido o protocolo anestésico com xilazina a $10 \%$ na dose de $0,05 \mathrm{mg} / \mathrm{kg}$ para a sedação parcial, em seguida bloqueio local com lidocaína a $2 \%$ no cordão espermático e vários pontos infiltrativos na linha de incisão. O paciente foi contido no solo em decúbito lateral direito em seguida foram realizadas tricotomia e antissepsia com solução degermante a $10 \%$ de iodopolividona, solução tópica de iodo a $1 \%$ e álcool $70 \%$ posteriormente o local foi envolto por campo cirúrgico estéril.

Optou-se pela técnica de incisão lateral do escroto para acessar o testículo comprometido, a ligadura do cordão espermático foi realizada com fio categute no sendo o mesmo empregado para abolição do espaço morto, para a síntese da pele utilizou-se fio de nylon n⿳⺈ em pontos tipo Wolff.

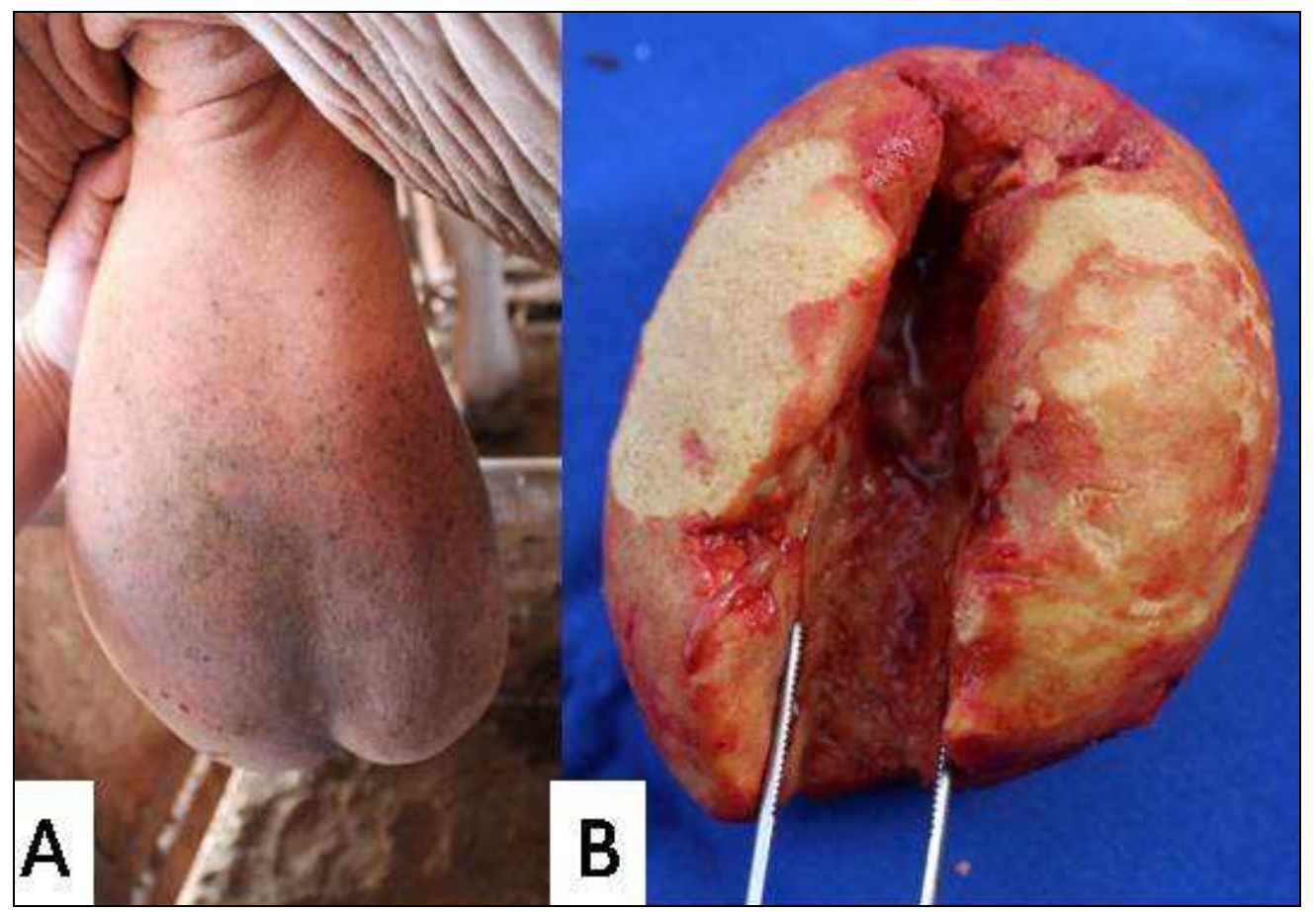

FIGURA 1: A -Escroto bovino com evidente aumento testicular esquerdo. B - Testículo esquerdo, após a remoção cirúrgica, com área cavitária no parênquima testicular. 
Ao término da intervenção foram coletados fragmentos testiculares, que foram armazenados em solução Bouin, e posteriormente processados para técnica histológica de rotina.Como tratamento pós-cirúrgico foi prescrito antibiótico a base de Benzilpenicilina Procaína na dose de $10.000 \mathrm{Ul} / \mathrm{Kg}$ durante 7 dias, associado a anti-inflamatório Flunixim Meglumine na dose de 2,2 mg/Kg por 5 dias. Noventa dias após o tratamento cirúrgico foi realizada nova coleta espermática para verificação da eficácia do tratamento.

\section{RESULTADOS E DISCUSSÃO}

Durante o exame ultrassográfico foi evidenciada uma cavidade no parênquima testicular com $1,4 \mathrm{~cm}$ de largura (Figura 2) e comprimento de praticamente toda a extensão longitudinal testicular, que pode ser comprovado após 0 ato cirúrgico (Figura 1B).

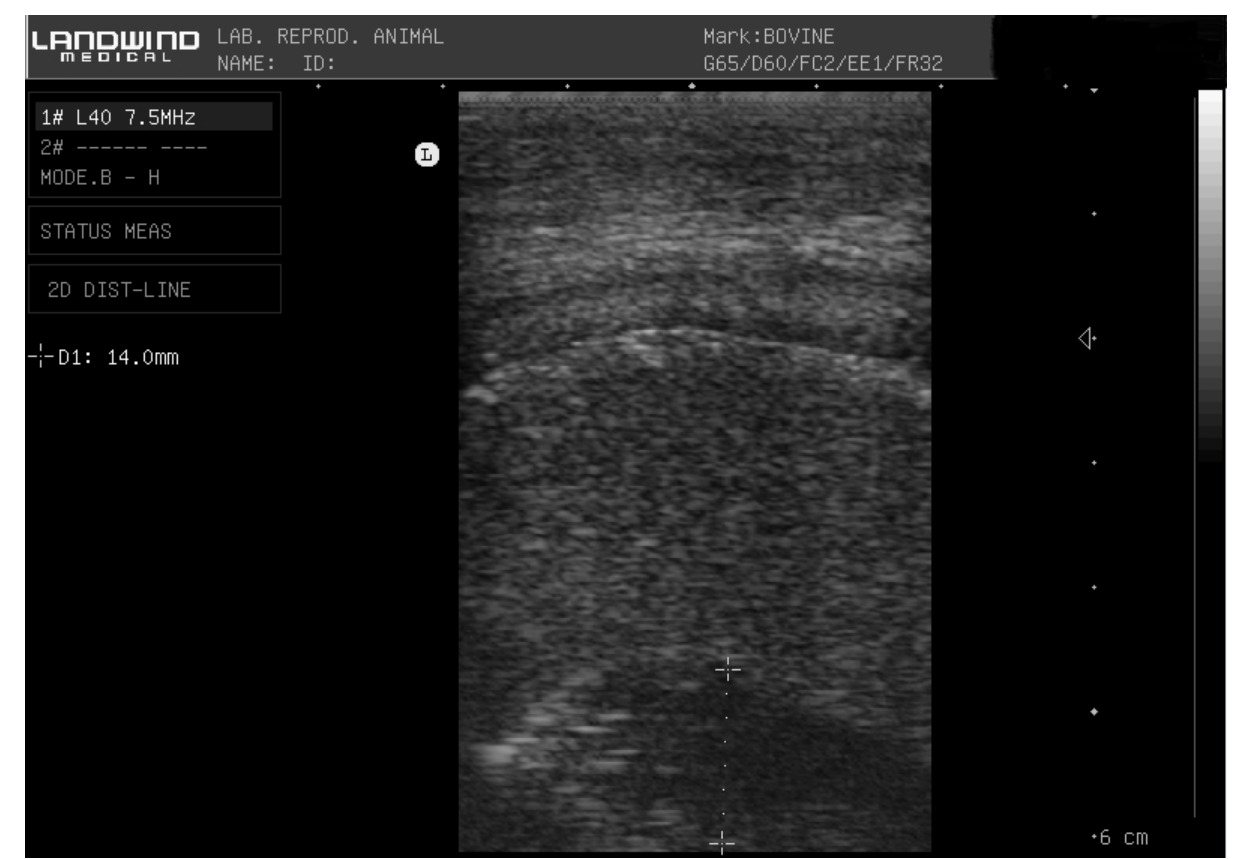

FIGURA 2: Imagem ultrassonográfica evidenciando, na porção inferior, uma cavidade localizada no parênquima testicular.

$\mathrm{Na}$ avaliação da lâmina histológica do testículo orquiectomizado observou-se pontos de necrose hemorrágica, sendo esta uma confirmação da degeneração testicular. No corte histológico do testículo observou-se extensa área de necrose coagulativa, sendo possível individualizar a arquitetura dos túbulos seminíferos, porém com os núcleos das células de linhagem fragmentados (Figura 3). 


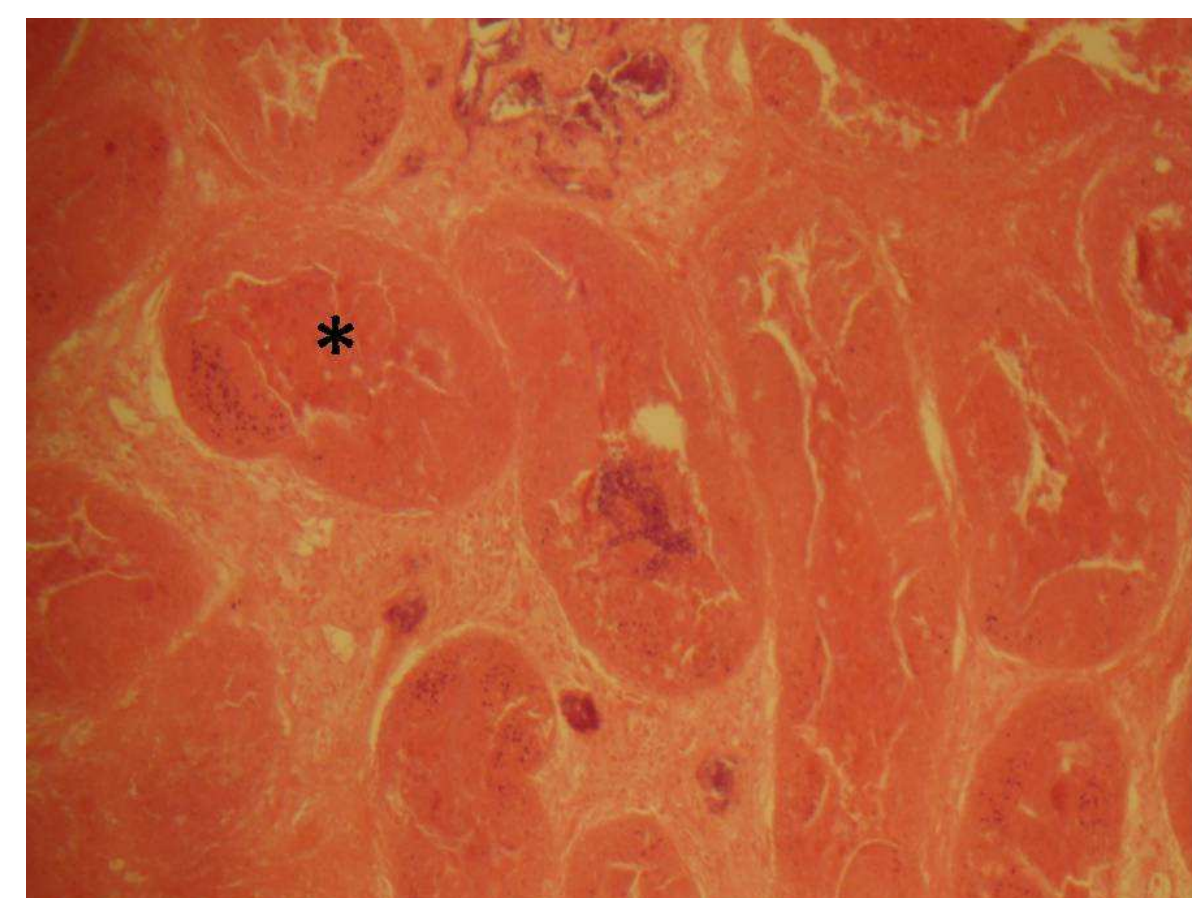

FIGURA 3: Necrose coagulativa dos túbulos seminíferos (asterisco) com degeneração do epitélio e arquitetura do tecido preservado. Testículo Bovino. Objetiva de 4x. Coloração Hematoxilina e Eosina.

$\mathrm{Na}$ região onde o tecido sofreu invaginação e formou-se uma cavidade, a análise histopatológica evidenciou proliferação de tecido conjuntivo neoformado, presença de neovasos e infiltrado inflamatório mononuclear (Figuras 4 e 5).

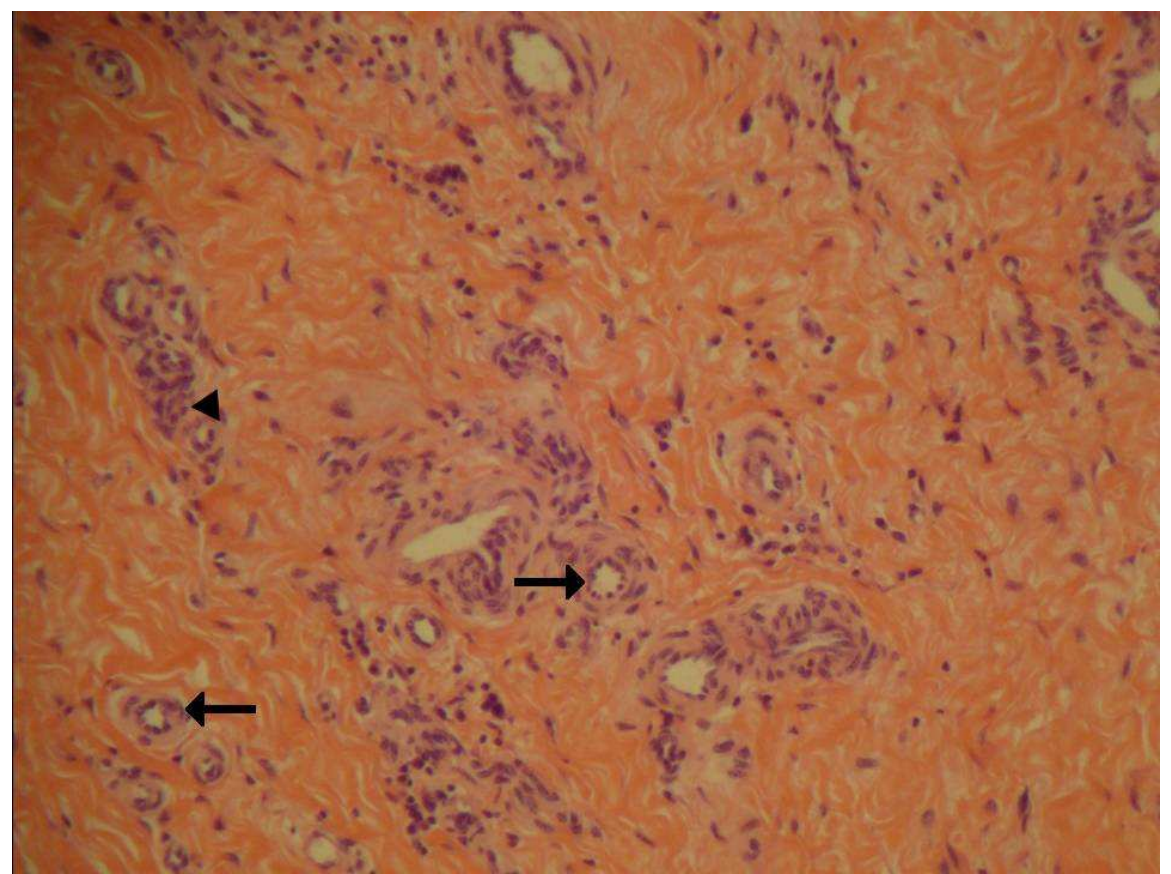

FIGURA 4: Área de fibrose testicular. Observa-se neovascularização (setas) e infiltrado inflamatório mononuclear (cabeça da seta). Testículo de Bovino. Objetiva de 10x. Coloração Hematoxilina Eosina. 


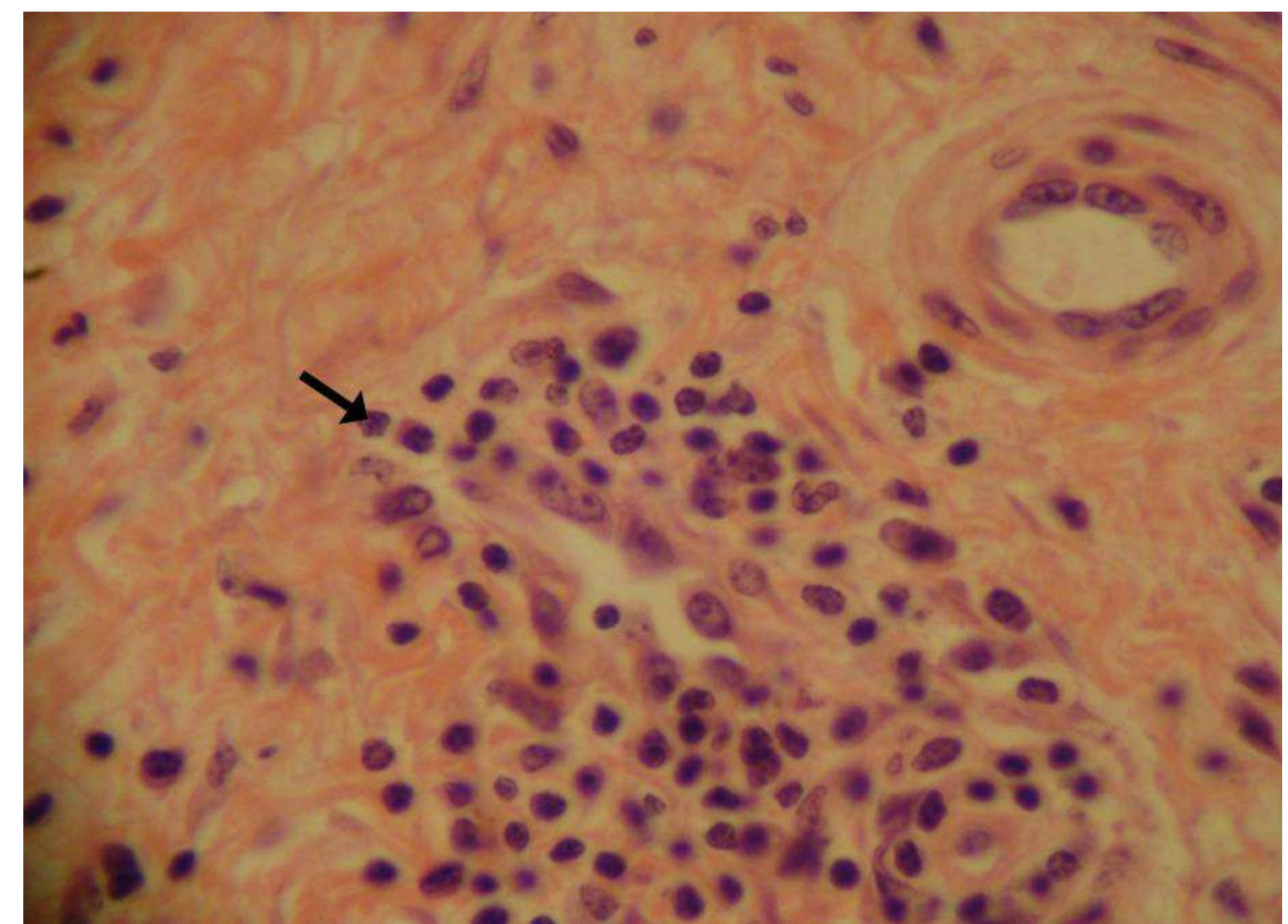

FIGURA 5: Área de fibrose testicular. Presença de infiltrado inflamatório mononuclear (seta). Testículo Bovino. Objetiva de 40x. Coloração de Hematoxilina e Eosina.

Com 90 dias pós-cirúrgico, coletou-se novamente uma amostra seminal, constatando-se uma melhora significativa nos padrões espermáticos com motilidade de $80 \%$, vigor 4 e turbilhonamento 3 . Também houve uma normalidade de problemas de morfologia espermática. O testículo remanescente apresentou-se anatomicamente normal quanto ao tamanho, consistência e mobilidade na bolsa testicular.

As principais causas da degeneração testicular são distúrbios de saúde quando associados de febre, toxemia ou infecção local, como também as alterações que aumentem a temperatura testicular. Além disso, fatores autoimunes, obstruções da cabeça do epidídimo, agentes químicos, físicos e multifatores hormonais que também predispõem um processo degenerativo testicular (NASCIMENTO \& SANTOS, 2011). Neste caso as alterações microscópicas observadas são sugestivas de lesão tecidual por hipóxia, provavelmente devido ao comprometimento da irrigação do órgão.

O aparecimento de células anormais inicia-se com células imaturas seguida de um aumento de cabeças isoladas normais, isto ocorre com cerca de 10 até 50 dias após o testículo sofrer uma injuria. As alterações espermáticas são associadas às alterações testiculares. A redução na consistência do testículo é um achado comumente associado nos casos de degeneração testicular, sendo decorrente da redução do epitélio seminífero. Quando a degeneração é leve ou moderada, há possibilidade de recuperação completa da função testicular, porque as espermatogônias juntamente com as células de Sertoli e Leydig possuem uma relativa resistência, permitindo assim o restabelecimento da espermatogênese por volta dos 60 dias após a remoção do agente patológico (NASCIMENTO \& SANTOS, 1997). Entretanto como evidenciado nos achados histológicos (Figuras 3, 4 e 5) a 
lesão neste caso foi grave, com perda de parênquima testicular e fibrosamento do órgão, impossibilitando a recuperação do testículo afetado.

A orquiectomia unilateral pode afetar o mecanismo de termorregulação do testículo remanescente, em consequência da inflamação provocada no local da incisão cirúrgica. SERAFINI et al., (2015) realizaram um experimento em nove garanhões orquiectomizados unilateralmente utilizando dois testes para avaliar a qualidade do DNA espermático, o ensaio do cometa e estrutura da cromatina espermática. As medidas foram comparadas antes da orquiectomia unilateral (0 dias) e aos 14,30 , e 60 dias após o procedimento cirúrgico, para determinar se o DNA espermático apresentou-se alterado após o testículo sofrer um leve estresse, embora os testes tradicionalmente utilizados para avaliar a qualidade do sêmen não terem apresentado alterações. Esses autores identificaram uma diminuição da qualidade do DNA espermático, tanto no teste do cometa quanto na estrutura da cromatina espermática, o que não foi identificado através dos métodos convencionalmente empregados na avaliação da qualidade do padrão espermático. Neste caso não foi realizada avaliação da estrutura do DNA espermático, que de fato pode ter ocorrido, uma vez que em quadros de uniorquiectomia há um certo aquecimento da região peritesticular que pode interferir no testículo remanescente, porém espera-se que haja uma normalização com o término do processo cicatricial.

BALL (2014) diagnosticou em um paciente humano por meio de ressonância magnética um tumor esclerosante de células de Sertoli, intratesticular esquerdo em seu polo superior medindo entre 6-7 milímetros. Com o intuito de preservar as funções testiculares e considerando o tamanho da massa tumoral, optou-se pela remoção parcial do testículo esquerdo. O autor salienta que quando houver um diagnóstico duvidoso e dadas proporções da afecção local, a orquiectomia radical continua a ser o procedimento de eleição corroborando com nosso trabalho onde se instaurou a orquiectomia unilateral total.

É sabido que a orquiectomia radical ainda é a técnica de eleição para o tratamento de tumores malignos de células germinativas, sendo estes a grande maioria associados às massas testiculares. Em pacientes diagnosticados com pequenas massas no testículo a cirurgia conservadora testicular (CCT) pode ser uma opção de tratamento alternativo para a orquiectomia radical. Com esse objetivo BORGUESI et al., (2015) realizaram uma revisão atualizada com base em relatos de caso de outros profissionais da medicina humana para avaliar as indicações atuais da CCT e discutir os resultados oncológicos e funcionais dos pacientes submetidos a esta técnica. Na literatura utilizada pelo autor cerca de 230 casos de massas testiculares foram descritas em sua maioria de origem benigna, a CCT apresentou resultados satisfatórios e promissores, também quando empregado em pequenas massas malignas em casos selecionados que a médio e longo prazo não demostraram nenhum risco significativo de recidivas locais e o testículo contralateral exerceu um efeito compensatório mantendo as funções hormonais em níveis normais. No entanto o testículo deste estudo apresentava uma lesão invaginante (Figura 1B) bastante extensa que inviabilizaria a orquiectomia parcial.

SOMMERS \& WINTER (2014) realizaram um estudo para analisar a anatomia e os achados de massas escrotais em pacientes humanos empregando o exame ultrassonográfico, pois quando uma massa escrotal é diagnosticada deve-se levar em consideração a presença de um neoplasma testicular. Sendo assim, o exame ultrassonográfico é a técnica ideal para avaliar o testículo nesta situação por ser um equipamento disponível, sem radiação e com sensibilidade de $98 \%$ para detectar 
este tipo de alteração testicular, pois quando uma massa escrotal é diagnosticada o principal objetivo do exame ultrassonográfico é indicar sua localidade intra ou extratesticular, no geral massas intratesticular são consideradas malígnas em contra partida massas extratesticular e císticas em sua maioria são benignas. Os autores salientam que os tumores testiculares são divididos em duas categorias: tumores de células germinativas (TCG) e tumores de estroma, sendo que os TCG são os responsáveis por $90 \%$ a $95 \%$ de todos os tumores testiculares. No presente relato foi detectado uma alteração ultrassonográfica cística (Figura 2), e não neoplásica de acordo com a histopatologia (Figuras 3, 4 e 5).

\section{CONCLUSÃO}

Quando há alteração testicular unilateral, com remoção do testículo afetado, o testículo contralateral pode suprir a produção espermática e manter as funções hormonais. Portanto, a técnica de orquiectomia unilateral pode ser viável para touros que apresentam grave degeneração testicular unilateral.

\section{REFERÊNCIAS}

BALL, A. J. Partial orchiectomy for the treatment of a benign sclerosing sertoli cell tumor: A report of a rare tumor in association with testicular microlithiasis. Urology Case Reports, v.3, p. 15-17, 2015.

BICUDO, S. D.; SIQUEIRA, J. B.; MEIRA, C. Patologias do sistema reprodutor de touros. Biológico. São Paulo, v.69, n.2, p.43-48, 2007.

BORGHESI, M.; BRUNOCILLA, E.; SCHIAVINA, R.; GENTILE, G.; DABABNEH, H.; MORA, L. D.; PRETE, C. D.; FRANCESCHELLI, A.; COLOMBO, F.; MARTORANA, G. Papel de la cirugía conservadora testicular en el manejo conservador de masas testiculares pequeñas: perspectivas oncológicas y funcionales. Actas Urológicas Españolas, v. 39, n. 1, p. 57-62, 2015.

CAMP, S. D. V. Common Causes of Infertility in the Bull. Veterinary Clinics of North America. Food animal Practice. v.13, n. 2, p. $203-231,1997$.

CBRA. Manual para exame andrológico e avaliação de sêmen animal. Colégio Brasileiro de Reprodução Animal. 1a Edição, 1997, Belo Horizonte - MG.

NASCIMENTO, E. F.; SANTOS, R. L. Patologia da reprodução dos animais domésticos. Guanabara Koogan, Rio de Janeiro, p. 108, 1997.

NASCIMENTO, E. F.; SANTOS, R. L. Patologia da reprodução dos animais domésticos. 3ed. Guanabara Koogan. Rio de Janeiro, p. 133, 2011.

SERAFINI, R.; VARNER, D. D.; BISSETT, W. JR.; BLANCHARD, T. L.; TEAGUE, S. R.; LOVE, C. C. Sperm DNA quality evaluated by comet assay and sperm chromatin structure assay in stallions after unilateral orchiectomy. Theriogenology, v. 30, p. 15, 2015. 
SOMMERS, D.; WINTER, T. Ultrasonography Evaluation of Scrotal Masses. Radiologic Clinics North America, v. 52, p. 1265-1281, 2014. 